\title{
Interactions Between Root Rotting Phytophthora, Abies Christmas Trees, and Environment
}

\author{
Kathleen M. McKeever ${ }^{1, \dagger}$ and Gary A Chastagner ${ }^{2}$ \\ ${ }^{1}$ USDA Forest Service, Forest Health Protection, Southern Region, Asheville, NC 28806; and ${ }^{2}$ Department of Plant Pathology, \\ Washington State University Puyallup Research and Extension Center, Puyallup, WA 98371
}

\begin{abstract}
Defining host-pathogen interactions between species of root-rotting Phytophthora and Abies in Christmas tree production areas is important for tailoring management activities on a regional scale and for developing molecular tools for identifying resistant host species. Classifying Abies species as resistant or susceptible is complicated by regional variation in abundance and aggressiveness of Phytophthora species and the influence of environment on symptom expression and host vigor. Because previous studies performed to assess host response to Phytophthora root rot (PRR) have focused on one or a few species of either the host or pathogen, a multifactorial experiment was conducted to assess the responses of seven species of Abies challenged with three isolates each of four Phytophthora

species under contrasting temperature conditions. Evaluation of mortality, root rot severity, and remaining root biomass after 16 weeks of exposure to the pathogen confirmed prior inferences regarding inherent variation in the resistance responses of various species of Abies and demonstrated evidence of variation in aggressiveness among species of Phytophthora as well as different isolates of the same Phytophthora species. The ambient temperatures at which studies were conducted had a conspicuous effect on host mortality, root rot severity, and radial growth of Phytophthora. Understanding how host responses differ under variable pathogen attack and ambient environment will improve efforts to control PRR using host species substitutions on infested ground.
\end{abstract}

Phytophthora root rot (PRR) is a serious disease of true fir (Abies spp.), resulting in substantial losses in the Christmas tree and conifer nursery industries (Chastagner and Benson 2000; McKeever and Chastagner 2016). Despite the availability of select chemical alternatives and cultural control methods, practical options for reducing PRR losses in Christmas tree farms are scarce, and their utilization may be limited by expense or feasibility of execution (Frampton and Benson 2012). Extreme susceptibility of Fraser (Abies fraseri [Pursh] Poir.) and noble (A. procera Rehder) firs often exceeds the practical efficacy of existing control measures available to Christmas tree farmers and has dictated grower abandonment of Phytophthora-infested land for cultivation of these highly desirable species (McKeever and Chastagner 2016). Increased demand by Christmas tree consumers for susceptible species, and the necessity for growers of live Christmas trees to remain relevant in competition with artificial tree industries, has spurred investigation into ways to reclaim infested acreage.

Recommending PRR-resistant Abies species and developing genomic tools to identify resistance to PRR are attractive mitigation options that rely on the ability to definitively assign a host resistance phenotype that is robust over a range of external influences. Host phenotype designation in the PRR pathosystem is fraught with complicating factors including variation in Phytophthora species aggressiveness and the fact that Phytophthora species compositions differ among U.S. Christmas tree-growing regions. Also, because climates differ in various parts of the country, factors such as heat and

${ }^{\dagger}$ Corresponding author: Kathleen M. McKeever;

E-mail: kmckeever@fs.fed.us

Funding: Funding was provided by Pacific Northwest Christmas Tree Association, Washington State Department of Agriculture (Specialty Crops Block Grant, Agreement Number K950), and USDA NIFA Specialty Crops Research Initiative program (PPNS\# 0733, Department of Plant Pathology, College of Agricultural, Human, and Natural Resources Sciences, Agricultural Research Center, Hatch Project No. WNP00388, Washington State University, Pullman, 99164-6430).

Accepted for publication 18 September 2018.

This article is in the public domain and not copyrightable. It may be freely reprinted with customary crediting of the source. The American Phytopathological Society, 2019. moisture stress influence host vigor, pathogen communities, and thus potential resistance expression.

Studies that have been conducted to characterize Abies resistance to PRR illustrate a need for a comprehensive approach to unify multiple contributing factors into an experiment in which phenotype can be interpreted within a controlled context. A history of testing Abies seedlings under lathe house conditions by researchers at North Carolina State University using a North Carolina isolate of $P$. cinnamomi Rands has indicated little to no resistance to $P$. cinnamomi in North American firs but good survival of the exotic momi (A. firma Siebold \& Zucc.), Himalayan (A. pindrow [Royle ex D. Don] Royle), Siberian (A. sibirica Ledeb.), and Turkish firs (A. bornmuelleriana Mattf.) (Frampton and Benson 2004, 2012; Hinesley et al. 2000; Shew and Benson 1981). Surveys of field-grown Turkish fir in northwestern North Carolina and northern California indicate that although seedlings of this species tolerate Phytophthora inoculation experimentally, they routinely succumb to $P$. cinnamomi in Christmas tree production areas where $P$. cinnamomi is pervasive (McKeever and Chastagner 2016). A field study in Washington state that evaluated 11 Abies spp. for root rot and stem cankers caused by Phytophthora spp. commonly found in Pacific Northwest bareroot nurseries corroborated findings regarding the aggressiveness of $P$. cinnamomi but also classified $P$. cactorum (Lebert \& Cohn) J. Schröt., P . cambivora (Petri) Buisman, and $P$. cryptogea Pethybr. \& Laff. as similarly virulent (Chastagner et al. 1990). P. cambivora was the most abundantly isolated species from field-grown noble and Fraser firs during collections from Christmas tree operations in western Washington and Oregon, suggesting its prevalence in these areas and virulence on these species (McKeever and Chastagner 2016). Experimental differences in disease development owing to isolate choice was illustrated on conifer seedlings for nine Phytophthora species in the Pacific Northwest (Hamm and Hansen 1982), and Campbell and Hamm (1989) supported the trends of variation in Phytophthora spp. aggressiveness even on non-Abies conifers. These research results suggest that to elucidate host phenotypes for Abies infected with Phytophthora across U.S. Christmas tree growing regions, it is necessary to design a study to incorporate combinations of host and pathogen species under conditions that reflect variations in regional climates.

In an effort to satisfy this need, a multifactorial greenhouse experiment was implemented in which seven Abies species were inoculated with three isolates of each of four Phytophthora species at 
two temperatures. The goals of this study were to (i) quantify root rot severity and mortality within an Abies species owing to inoculation with four different Phytophthora species, (ii) investigate how temperature affects the overall rates and sums of mortality, (iii) observe differences in root rot severity and mortality in response to infection by different isolates of a Phytophthora species, (iv) evaluate visual root rot severity ratings and rootball dry weights for their usefulness in predicting mortality, (v) relate radial growth of Phytophthora isolates in vitro to virulence in vivo, and (vi) interpret host resistance with respect to Phytophthora species and temperature to improve recommendations to Christmas tree growers about which Abies species will survive best under local environmental conditions and Phytophthora populations.

\section{Materials and Methods}

Experimental design. Four species of Phytophthora were used to challenge seven Abies spp. at two temperature ranges. A cool temperature range of 15 to $21^{\circ} \mathrm{C}$ (further referred to as $15^{\circ} \mathrm{C}$ ) was chosen to simulate environmental conditions that may be encountered yearround in more temperate geographic locations such as the Pacific Northwest, or at cooler times of the growing season in other locations. A warm temperature range of 27 to $32^{\circ} \mathrm{C}$ (further referred to as $27^{\circ} \mathrm{C}$ ) was chosen to suggest the typical summertime temperatures encountered in many U.S. Christmas tree growing regions. Assessing PRR at two different temperatures required that the experiment be arranged in two separate greenhouses. Because variation exists among isolates within a given Phytophthora species (Eggers et al. 2012; Granke et al. 2011), the experiment was partitioned into three simultaneously running experiments, each employing a different isolate of the four Phytophthora species. Five replicate blocks of each Phytophthora/Abies combination were executed at each temperature.

Each of the four species of Phytophthora plus one noninoculated control treatment were randomly assigned within each replicate block. Within each Phytophthora species subdivision, three geographically distinct isolates of that given Phytophthora were randomly distributed. Inoculum of each species $\times$ isolate treatment (or a noninoculated treatment) was applied to a set of seven different fir species. Each species of fir was made up of five individual seedlings representing an experimental unit, of which collected data points were averaged to generate a single measurement. Because the experimental units (composed of five trees) were replicated in each of five blocks, the blocks constituted five true replicates with measurements that were not averaged.

Seedlings. The seven species of Abies assessed in this study represent the most commonly grown and economically important Christmas tree species for U.S. markets. Five of the species are native to North America: Fraser, noble, white (A. concolor [Gordon] Lindley ex Hildebrand), Canaan (A. balsamea var. phanerolepis Fern.), and balsam firs (A. balsamea [L.] Mill.). The two remaining species used in this experiment, Turkish and Nordmann fir (A. nordmanniana [Steven] Spach), are native to the Caucasus Mountains spanning northern Turkey and western Eurasia and belong to the A. nordmanniana complex. Seedlings were obtained in February 2014 and 2015 from the Weyerhaeuser Corporation's Rochester Nursery (Rochester, WA). The five North American species were grown as 1-year-old containerized stock (P-0). Owing to the small size of P0 Nordmann and Turkish fir seedlings, 2-year-old bareroot seedlings $(\mathrm{P}+1)$ of similar size to the $\mathrm{P}-0$ stock of the other five species were used. All seedlings were received frozen and physiologically dormant. In June of each year, thawed seedlings were transplanted into 262-ml D16L Deepots (Stuewe \& Sons, Tangent, OR) using a custom conifer potting mix prepared by Specialty Soils (Covington, WA) (Table 1). Planted seedlings were placed into D50T 50-cellcapacity support trays and maintained outdoors from June through October on elevated lumber-and-cinder benches underneath $50 \%$ shade cloth. Irrigation was initiated via overhead sprinkler two times daily for $20 \mathrm{~min}$ increments for the first 2 weeks during transplant establishment and subsequently thereafter during hot spells $\left(>29^{\circ} \mathrm{C}\right)$. A regular outdoor watering schedule was maintained once daily with a 15-min duration during temperate weather. Two times during the outdoor storage period, seedlings were treated with fludioxonil (Medallion, Syngenta Crop Protection, Greensboro, NC) applied as

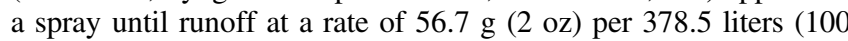
gal) of water for the prevention of gray mold (Botrytis cinerea Pers.) during storage. In early October, as seedlings were entering dormancy following terminal bud development, the seedlings - still potted in the Deepots-were packaged in wax-coated seedling boxes to undergo an artificial vernalization period at $3{ }^{\circ} \mathrm{C}$ in the dark for $800 \mathrm{~h}$ (approximately 4 weeks). This vernalization period allowed for experiments to be conducted on dormant seedlings and ensured consistent budbreak upon resumption of physiological activity. Upon termination of the vernalization period, seedlings were removed from the boxes, labeled with pull-through tree tags, and randomized into the two greenhouses where experiments were to be conducted. During the 3-week period between introduction into the greenhouses and initiation of the experiment, greenhouse conditions were kept at a cool temperature between 12 and $15^{\circ} \mathrm{C}$ with no artificial lighting and drawn shade cloth to allow for easy transition from coldstorage temperatures to the warm, lighted temperatures that would be implemented during the experiment. Irrigation during this transitional period was applied once daily for $10 \mathrm{~min}$ durations at a rate of $0.25 \mathrm{ml} / \mathrm{min}$.

Selection of Phytophthora species and isolates. Phytophthora cultures used for inoculum in this study were sourced from a nationwide collection of root-rotting Phytophthora from Abies in Christmas tree farms conducted during a 2-year period from 2012 to 2013 (McKeever and Chastagner 2016). It was decided that the four most commonly occurring Phytophthora species from this survey would be selected to constitute the inoculum. These species included $P$. cambivora (11 isolates), $P$. cinnamomi (seven isolates), $P$. kelmania (seven isolates), and $P$. pini Leonian (four isolates) (McKeever and Chastagner 2016). Because several isolates of each of the four Phytophthora species were collected, virulence testing was performed to acquire the three most aggressive isolates of each species to test concurrently in the planned greenhouse experiment. Table 2 provides information on the origins and NCBI identities of each isolate employed in the virulence assessment. Lesion lengths resulting from seedling stem inoculations were chosen to infer virulence, because this is an established method for Phytophthora that correlates well to aggressiveness on roots (Bhat et al. 2006; Weiland et al. 2010).

Prior to assessing virulence, all collected isolates of the four Phytophthora spp. of interest were inoculated onto noble fir branches in a preemptive effort to maximize wild-type virulence after repeated subculturing on artificial media (Hodgson and Sharma 1967). For

Table 1. Bulk custom soil mix prepared by Specialty Soils (Covington, WA) used to pot seedlings for all experiments

\begin{tabular}{|c|c|}
\hline Quantity per m² & Component \\
\hline $2 \%$ & Diatomaceous earth \\
\hline $27.84 \%$ & Saskatchewan sphagnum peat \\
\hline $17.5 \%$ & Pumice \\
\hline $5 \%$ & Nitrified alder sawdust \\
\hline $50 \%$ & Aged fine bark (hemlock and fir) \\
\hline $0.113 \mathrm{~kg}$ & M-ROOTS 3-3-3 (mycorrhizae endo/ecto) \\
\hline $0.005 \mathrm{~kg}$ & Treflan 10G \\
\hline $0.172 \mathrm{~kg}$ & Calcium nitrate $\left(\mathrm{Ca}\left[\mathrm{NO}_{3}\right]_{2}\right)(15.5-0-0)$ \\
\hline $0.131 \mathrm{~kg}$ & Potassium sulfate $\left(\mathrm{K}_{2} \mathrm{SO}_{4}\right)(0-0-53)$ \\
\hline $0.127 \mathrm{~kg}$ & Ammophos $\left(\mathrm{NH}_{4} \mathrm{H}_{2} \mathrm{PO}_{4}\right)(11-52-0)$ \\
\hline $0.376 \mathrm{~kg}$ & Ferrous sulfate $\left(\mathrm{FeSO}_{4}\right)(20 \% \mathrm{Fe})$ \\
\hline $2.494 \mathrm{~kg}$ & Plantacote $(14-9-15)+\mathrm{S}$ (4-mo. release) \\
\hline $0.172 \mathrm{~kg}$ & Agricultural gypsum $\left(\mathrm{CaSO}_{4} 2 \mathrm{H}_{2} \mathrm{O}\right)$ \\
\hline $1.700 \mathrm{~kg}$ & Limestone flour \\
\hline $2.721 \mathrm{~kg}$ & Dolomite lime \\
\hline $14.78 \mathrm{ml}$ & Manganese sulfate $\left(\mathrm{MnSO}_{4}\right)(2.5 \% \mathrm{Mn})$ \\
\hline $3.84 \mathrm{ml}$ & Sodium molybdate $\left(\mathrm{Na}_{2} \mathrm{MoO}_{4}\right)(2.0 \% \mathrm{Mo})$ \\
\hline $29.57 \mathrm{ml}$ & Fritted micronutrients \\
\hline $31.64 \mathrm{ml}$ & TriCure media surfactant \\
\hline
\end{tabular}


restorative inoculations, all isolates of a single Phytophthora species were inoculated onto different branches of the same field-grown noble fir. Inoculations were made in the second year's internodal region of a branch by scoring the wood with a 5-mm-diameter cork borer and peeling back the thin bark layer to expose the phloem underneath. A 5-mm-diameter plug from an actively growing 5-day-old culture on V8 medium was applied facedown to the phloem, and the bark layer was replaced. Inoculation sites were sealed with sterile petroleum jelly, wrapped in moist sterile cotton, and fastened with Parafilm (Bemis, Neenah, WI). Inoculation sites were allowed to incubate on the tree for 14 days at ambient outdoor temperatures averaging $19^{\circ} \mathrm{C}$ (diurnal fluctuations $\pm 7^{\circ} \mathrm{C}$ ) with $71 \%$ average relative humidity. After 14 days, samples were taken from the margins of the lesioned and healthy tissues surrounding the inoculation sites, surface sterilized with a $1: 10$ solution of $8.25 \% \mathrm{NaClO}$ to sterile deionized water, and plated into PARPH-clarified V8 (cV8) semiselective medium (15 g of Difco agar, $33 \mathrm{ml}$ of clarified V8 juice, $10 \mathrm{mg}$ of Delvocid salt [50\% pimaricin], $250 \mathrm{mg}$ of sodium ampicillin, $10 \mathrm{mg}$ of rifampicin sodium salt, $67 \mathrm{mg}$ of Terraclor [75\% pentachloronitrobenzene], and $50 \mathrm{mg}$ of hymexazol in 1 liter water). Resulting cultures were transferred to unamended $\mathrm{cV} 8$ medium.

Virulence testing was performed on actively growing 2-year-old bareroot noble fir seedlings that had been transplanted into 1-liter MT38 Treepots (Stuewe \& Sons) and maintained outdoors for 4 weeks prior to use. Virulence testing was performed in August 2014 in a randomized complete block design with three seedlings constituting an experimental unit and three replications (blocks) of each treatment. The experiment was repeated once. Height and diameter measurements were recorded for each seedling in an effort to choose uniform plants for inoculations. Inoculations were performed on the stem of the seedling approximately $12 \mathrm{~cm}$ above the soil line, and techniques were identical to the restorative isolations described above. Treatments were randomized within each block, and seedlings were incubated in a $17^{\circ} \mathrm{C}$ greenhouse for 7 days with shade cloth drawn and no supplementary lighting. Overhead irrigation was applied for $10 \mathrm{~min}$, once a day, at a rate of $0.25 \mathrm{ml} / \mathrm{min}$. After 7 days, resulting lesions were exposed by carefully scraping back the bark starting at the point of inoculation and extending to the perimeters of the lesion. Lesion lengths were measured with digital calipers.

For the final 12 isolates (three isolates of each of the four species of Phytophthora) that were selected based on stem lesion lengths, radial growth measurements were assessed at two different temperatures corresponding to the two experimental temperatures. Because the cool temperature ranged from 15 to $21^{\circ} \mathrm{C}$ and the warm temperature ranged from 27 to $32^{\circ} \mathrm{C}$ in two separate greenhouses, incubators were set to the midpoint values of 17 and $29^{\circ} \mathrm{C}$ for the culture radial growth assessments. Plugs (4-mm diameter) of each isolate were grown on $\mathrm{cV} 8$ medium in three replicate Petri dishes. Radial growth $(\mathrm{mm})$ in two opposing directions was recorded $24 \mathrm{~h}$ after plating and then daily for up to 8 days. Measurements for opposing directions of each plate and for the three replicate plates were averaged for each isolate. This assay was repeated once.

Inoculation. Colonized rice grains were used to apply experimental treatments to seedlings (Holmes and Benson 1994). For each treatment, $8 \mathrm{~g}$ of long-grain white rice were mixed with $5.76 \mathrm{ml}$ of deionized water in a $250-\mathrm{ml}$ flask, autoclaved twice, and seeded with six 3-mm-diameter plugs taken from the edges of 4-day-old cultures grown on $\mathrm{cV} 8$ medium. Noninoculated treatments received six plugs of noncolonized cV8. Flasks were incubated at room temperature for 21 days, with agitation on alternating days to break up rice mats and evenly distribute inoculum. A separate set of 15 flasks (three isolates each of four Phytophthora spp. and three noncolonized control flasks) was produced for each replicate block, totaling 75 flasks for each greenhouse. Seedlings were inoculated by inserting a single rice grain in each of three holes in the planting substrate that were positioned around the stem of the seedling and angled toward the rootball to a depth of $10 \mathrm{~cm}$. A single flask of inoculum was used to inoculate

Table 2. Cultures utilized for virulence testing of Phytophthora cambivora, $P$. cinnamomi, $P$. kelmania, and $P$. pini. Isolate ID number corresponds to the number of cultures obtained for each of the four Phytophthora species. Location of origin indicates city and state where the isolate was recovered. Host of origin indicates the species of Abies from which each Phytophthora isolate was obtained.

\begin{tabular}{|c|c|c|c|c|}
\hline Phytophthora species & Isolate ID & Location of origin & Host of origin & NCBI accession \\
\hline P. cambivora & 01 & Stayton, OR & A. procera & KU053253 \\
\hline P. cambivora & 02 & Mason County, MI & A. fraseri & $\ldots$ \\
\hline P. cambivora & 03 & Tacoma, WA & A. procera & KU053263 \\
\hline P. cambivora & 04 & Puyallup, WA & A. procera & KU053270 \\
\hline P. cambivora & 05 & Salem, OR & A. procera & KU220617 \\
\hline P. cambivora & 06 & Stayton, OR & A. procera & KU053251 \\
\hline P. cambivora & 07 & Maple Valley, WA & A. procera & KU053259 \\
\hline P. cambivora & 08 & Eatonville, WA & A. procera & KU053260 \\
\hline P. cambivora & 09 & Stayton, OR & A. procera & KU053252 \\
\hline P. cambivora & 10 & Enumclaw, WA & A. procera & KU053264 \\
\hline P. cambivora & 11 & Canby, OR & A. procera & KU053255 \\
\hline P. cinnamomi & 01 & Placerville, CA & A. equi-trojani & KU053228 \\
\hline P. cinnamomi & 02 & Placerville, CA & A. concolor & KU053229 \\
\hline P. cinnamomi & 03 & Placerville, CA & A. nordmanniana & KU053227 \\
\hline P. cinnamomi & 04 & Camino, CA & A. nordmanniana & KU053226 \\
\hline P. cinnamomi & 05 & Raleigh, NC & A. fraseri & $\ldots$ \\
\hline P. cinnamomi & 06 & Raleigh, NC & A. bornmuelleriana & KU220613 \\
\hline P. cinnamomi & 07 & Raleigh, NC & A. equi-trojani & KU220612 \\
\hline P. kelmania & 01 & Litchfield, CT & A. fraseri & KU053233 \\
\hline P. kelmania & 02 & Groton, NY & A. fraseri & KU053242 \\
\hline P. kelmania & 03 & Groton, NY & A. fraseri & KU220615 \\
\hline P. kelmania & 04 & Groton, NY & A. fraseri & KU053244 \\
\hline P. kelmania & 05 & Manitowoc County, WI & A. balsamea var. phanerolepis & $\ldots$ \\
\hline P. kelmania & 06 & Jefferson, NC & A. bornmuelleriana & KU053247 \\
\hline P. kelmania & 07 & Jefferson, NC & A. fraseri & KU053249 \\
\hline P. pini & 01 & Warren, CT & A. balsamea var. phanerolepis & KU053230 \\
\hline P. pini & 02 & Groton, NY & A. fraseri & KU053241 \\
\hline P. pini & 03 & Allegan County, MI & A. fraseri & AY995350 \\
\hline P. pini & 04 & Jefferson, NC & A. fraseri & KU053248 \\
\hline
\end{tabular}


all seven fir species receiving a given treatment in a single block. After 8 weeks of incubation, a second inoculation was performed on living trees following the above protocol. This second inoculation was implemented as a precaution to ensure that surviving seedlings were not simply disease escapes resulting from the failure of inoculum to contact roots.

Incubation conditions. For the first 5 days immediately following both inoculation periods, overhead irrigation was applied at a rate of $0.25 \mathrm{ml} / \mathrm{min}$ for $60 \mathrm{~min}$ durations twice per day to create saturated soil conditions conducive to PRR (Kuan and Erwin 1980; Rhoades et al. 2003). After this initial saturation period, irrigation was reduced to a 20 min period, once daily. To comply with USDA Animal and Plant Health Inspection Service regulations, irrigation runoff was collected and disinfested with $8.25 \%$ NaClO. A 12-h photoperiod was maintained throughout the duration of the experiment using 400-W high-pressure sodium greenhouse lights at an average intensity of $178 \mu \mathrm{mol} \cdot \mathrm{s}^{-1} \cdot \mathrm{m}^{-2}$. Greenhouse temperatures were programmed to remain within dictated degree ranges throughout a 24$\mathrm{h}$ period with no predetermined diurnal fluctuations. Cooling was achieved through automatic activation of exhaust fans and evaporative cooling. To preempt the possibility of infestation by Botrytis spp., trees were treated once during shoot elongation with fludioxonil at a rate of $56.7 \mathrm{~g}(2 \mathrm{oz})$ per 378.5 liters $(100 \mathrm{gal})$, and air circulation was maintained using four horizontal airflow fans positioned overhead in the four corners of each greenhouse. Ambient temperature and relative humidity were recorded with $\mathrm{HOBO}$ Pro data loggers (Onset Computer Corp., Bourne, MA) at the western and eastern ends of each greenhouse. Soil temperature was measured using HOBO 4-channel analog data loggers with probes inserted $7.6 \mathrm{~cm}$ into the soil of two individual seedlings in each block. Seedlings were undisturbed for 8 weeks following the first inoculation and then again for an additional 8 weeks following the second inoculation for a total duration of 16 weeks for the experiment. This experiment was repeated once in the following year.

Assessments. The onset of budbreak for each species was noted, and foliar assessments were made biweekly beginning at the onset of symptoms in the most susceptible species (approximately 19 days postinoculation) to estimate PRR incidence. Foliar ratings were made on an ordinal scale of $1=$ alive (green foliage, fully expanded new growth, full turgor), 2 = failing (wilt, chlorosis, failure to break bud, desiccation, partial necrosis), and $3=$ dead (fully necrotic foliage or severely wilted past the point of likely recovery).

At the 16-week conclusion of the experiment, seedlings were destructively processed to assess disease severity on the roots. All seedlings were carefully removed from Deepots, and root systems were washed free of potting media, taking care to retain as much root tissue as possible in severely damaged seedlings. The percent of rot on the root system was visually assessed on a 1 to 4 scale where $1=<25 \%$ rot, $2=25$ to $50 \%$ rot, $3=50$ to $75 \%$ rot, and $4=>75 \%$ rot. To estimate relative biomass reductions in comparison with noninoculated treatments, root systems were detached from the stem at the collar of the highest root and dried at $70^{\circ} \mathrm{C}$ for $72 \mathrm{~h}$ prior to weighing. To verify Phytophthora as the causal agent of mortality, root tip isolations were made on a subset of seedlings from each treatment in each block.

Data analysis. Analyses of variance (ANOVAs) of the various data sets generated by this research and mean separations among treatments were performed with SAS 9.4 (SAS Institute, Cary, NC). Graphical representations of data were achieved using R Statistical Software (R Foundation, Vienna, Austria). Analyses of variance of lesion size data from virulence testing assays were performed to compare isolates within each of the four Phytophthora species individually, using PROC MIXED procedures with posthoc mean separations using Tukey's honestly significant difference. Data from the



Fig. 1. Mean lesion sizes produced on noble fir seedling stems 7 days post-inoculation with various isolates of four Phytophthora species. Isolate identities and states of origin are listed along the x-axis for each Phytophthora species. Letters above bars serve as a notation to indicate significantly different lesion sizes produced by the various isolates within a Phytophthora species, as determined by Tukey's honestly significant difference post-hoc analysis. A different type of letter notation was used for each Phytophthora species to indicate that isolates were not compared between Phytophthora species but only within a Phytophthora species. Information on isolates is provided in Table 2. 
two trials were combined. For the greenhouse screening, data from the two greenhouses were assessed separately because of the lack of replication of temperature within a single year's trial. The three isolates of each Phytophthora species were also analyzed separately in each analysis, owing to the selected method of physical randomization and spatial setup within each greenhouse. For all comparisons of response variables among hosts and treatments, data from the fivetree experimental unit for each fir species in each treatment within a

Table 3. Rho and $P$ values from Pearson's product-moment correlation (PPMC) examine agreement of the three response variables assessed in this study (area under the disease progress curve [AUDPC], root rot rating [rot], and dry weight [wt.]) for each of the seven Abies species. Multiple linear regression (MLR) analysis indicates the predictive power of using rot and wt. to forecast AUDPC for each host species.

\begin{tabular}{|c|c|c|c|c|}
\hline \multirow[b]{2}{*}{ Abies species } & \multicolumn{3}{|c|}{ Pearson's PPMC } & \multirow{2}{*}{$\frac{\text { MLR }}{\text { AUDPC versus rot, wt. }}$} \\
\hline & AUDPC versus rot & AUDPC versus wt. & $\overline{\text { rot versus wt. }}$ & \\
\hline A. procera & $\begin{array}{l}r=0.97 \\
P<0.0001\end{array}$ & $\begin{array}{l}r=-0.74 \\
P<0.0001\end{array}$ & $\begin{array}{l}r=-0.81 \\
P<0.0001\end{array}$ & $\begin{array}{l}R^{2}=0.72 \\
P(\text { rot })=0.0002 \\
P(\text { wt. })=0.6326\end{array}$ \\
\hline A. fraseri & $\begin{array}{l}r=0.95 \\
P<0.0001\end{array}$ & $\begin{array}{l}r=-0.63 \\
P=0.0005\end{array}$ & $\begin{array}{l}r=-0.79 \\
P<0.0001\end{array}$ & $\begin{array}{l}R^{2}=0.79 \\
P(\text { rot })=0.0004 \\
P(\text { wt. })=0.0084\end{array}$ \\
\hline A. concolor & $\begin{array}{l}r=0.86 \\
P<0.0001\end{array}$ & $\begin{array}{l}r=-0.50 \\
P=0.009\end{array}$ & $\begin{array}{l}r=-0.74 \\
P<0.0001\end{array}$ & $\begin{array}{l}R^{2}=0.94 \\
P \text { (rot) }<0.0001 \\
P \text { (wt. })=0.0014\end{array}$ \\
\hline A. balsamea & $\begin{array}{l}r=0.86 \\
P<0.0001\end{array}$ & $\begin{array}{l}r=-0.72 \\
P<0.0001\end{array}$ & $\begin{array}{l}r=-0.80 \\
P<0.0001\end{array}$ & $\begin{array}{l}R^{2}=0.95 \\
P \text { (rot })<0.0001 \\
P(\text { wt. })=0.039\end{array}$ \\
\hline $\begin{array}{l}\text { A. balsamea var. } \\
\text { phanerolepis }\end{array}$ & $\begin{array}{l}r=0.86 \\
P<0.0001\end{array}$ & $\begin{array}{l}r=-0.82 \\
P<0.0001\end{array}$ & $\begin{array}{l}r=-0.74 \\
P<0.0001\end{array}$ & $\begin{array}{l}R^{2}=0.92 \\
P(\text { rot })<0.0001 \\
P(\text { wt. })=0.0034\end{array}$ \\
\hline A. nordmanniana & $\begin{array}{l}r=0.95 \\
P<0.0001\end{array}$ & $\begin{array}{l}r=-0.83 \\
P<0.0001\end{array}$ & $\begin{array}{l}r=-0.94 \\
P<0.0001\end{array}$ & $\begin{array}{l}R^{2}=0.87 \\
P(\text { rot })<0.0001 \\
P(\text { wt. })=0.054\end{array}$ \\
\hline A. bornmuelleriana & $\begin{array}{l}r=0.92 \\
P<0.0001\end{array}$ & $\begin{array}{l}r=-0.80 \\
P<0.0001\end{array}$ & $\begin{array}{l}r=-0.76 \\
P<0.0001\end{array}$ & $\begin{array}{l}R^{2}=0.76 \\
P \text { (rot) }<0.0001 \\
P \text { (wt. }=0.0608\end{array}$ \\
\hline
\end{tabular}

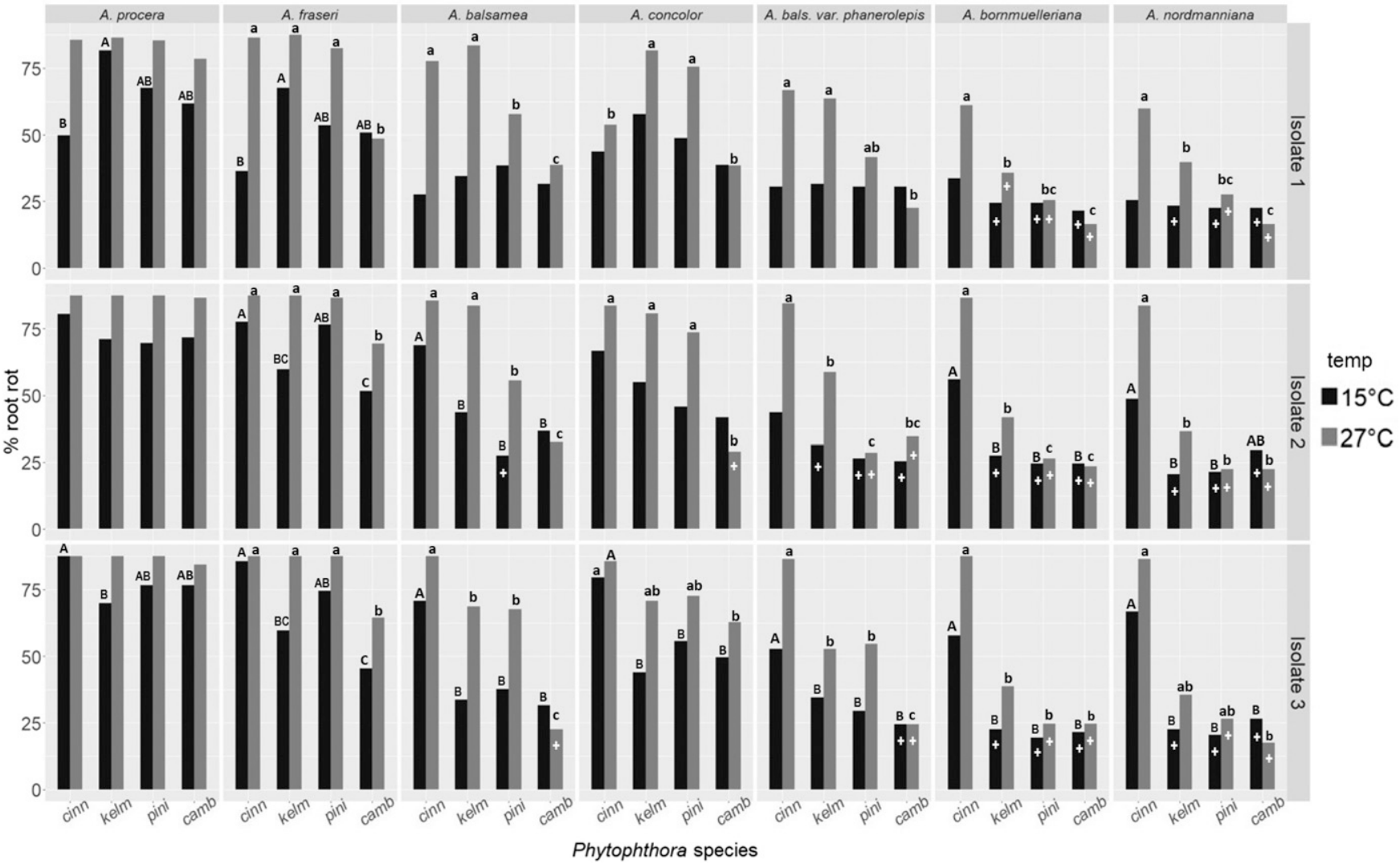

Fig. 2. Visual assessment of percent rot on the rootball caused by each Phytophthora species for each Abies species. The seven Abies species are arranged in vertical facets. Phytophthora isolates ( 1 to 3 for each species) are arranged in horizontal facets. The two temperatures are displayed adjacently but are not compared statistically. Lowercase letters above gray bars show mean separations between Phytophthora treatments at $27^{\circ} \mathrm{C}$ for the host indicated. Uppercase letters above black bars show mean separations between Phytophthora treatments at $15^{\circ} \mathrm{C}$ for the host indicated. Crosses on bars indicate treatments in which \% root rot did not differ significantly from controls. In instances in which there were no statistical differences among the four Phytophthora species, letters are absent from above histogram bars. Phytophthora species: cinn $=P$. cinnamomi; kelm $=P$. kelmania; and $c a m b=P$. cambivora. 
block were averaged to constitute a single measurement. Because there were five blocks in each greenhouse, each fir $\times$ Phytophthora combination had a total of five replicates for each isolate and temperature.

Biweekly foliar assessments from the greenhouse screening were summarized as a time course of percent mortality within each hosttreatment combination and used to construct disease progress curves (Madden et al. 2007). Mortality over time was used to calculate area under the disease progress curve (AUDPC), which in turn was used to compare mortality among host species in each treatment. AUDPC measurements were log transformed to achieve normality within a host species and linearize the data. The root rot severity categorical classes ( 1 to 4 ) were converted to their corresponding percentage ranges, and the midpoint value of each range was utilized for parametric statistical analysis (Campbell and Neher 1994; Horsfall and Barratt 1945). Dry weights, in grams, of the dried root systems were expressed as percentages of the control (noninoculated) treatments. ANOVA tests were performed to assess differences in each response variable among the different fir species within each treatment, as well as among the different treatments for each fir species individually. Pearson's product-moment correlation (PPMC) was used to assess harmony among the three response variables from the greenhouse Abies screening. For PPMC analysis, data from all trials, treatments, and temperatures were combined to understand how well the response variables represented each other, but they were also examined by each host species individually to assess differences. Root rot rating and dry weight response variables were regressed against AUDPC to test the null hypothesis that percent rot and root biomass remaining after infection are not indicative of disease development. This test was performed to gauge the predictive power of using data from these response variables to forecast disease progression.

Differences in radial growth rate of Phytophthora cultures at 15 and $27^{\circ} \mathrm{C}$ were compared using paired two-sample $t$ tests with data from both trials combined. Unequal variances were assumed owing to differences between the two temperatures in the number of days required for a given culture to reach the perimeters of the Petri plate.
Average radial growth rates were also regressed against percent mortality of each tree species at each temperature to determine if the speed of pathogen growth was correlated to tree death.

\section{Results}

Selection of Phytophthora inocula from virulence testing. Lesions on noble fir stems produced by $P$. cinnamomi ranged from 87.9 to $124.3 \mathrm{~mm}$ among seven isolates. Eleven $P$. cambivora isolates produced lesions that ranged from 9.6 to $68.4 \mathrm{~mm}$. Lesions ranged from 26.0 to $46.2 \mathrm{~mm}$ for seven $P$. kelmania isolates and from 33.8 to $49.9 \mathrm{~mm}$ among four $P$. pini isolates. The three isolates of each Phytophthora species producing the longest lesions were selected, except for $P$. cinnamomi, for which one less-virulent isolate was included in further experiments (Fig. 1).

Evaluating root rot severity rating and dry weight measurement as useful metrics for describing disease. PPMC analysis indicated that the root rot severity and dry weight metrics were strongly correlated with both disease progress and with each other (Table 3). As disease progressed, root rot rating severity increased $(r=0.93, n=182, P<0.0001)$ and dry weight root biomass decreased $(r=-0.71, n=182, P<0.0001)$. Similarly, as root rot severity increased, root biomass decreased $(r=-0.79, n=182, P<$ $0.0001)$. Overall significance of the multiple regression analysis $(P<0.0001)$ between the response and experimental variables dictated rejection of the null hypothesis; however, an insignificant $P$ value for the dry weight variable indicated that only the root rot rating was a reliable predictor of disease progress (Table 3).

Quantifying root rot severity and mortality owing to inoculation with four different Phytophthora species. Observational comparison of root rot severity owing to Phytophthora treatment for each host (Fig. 2) suggested a trend of greater damage on host roots inflicted by $P$. cinnamomi, followed by $P$. kelmania, $P$. pini, and $P$. cambivora. These trends were not absolute; for example, $P$. pini was quite virulent on noble and Fraser firs, causing nearly as much damage as $P$. cinnamomi and $P$. kelmania in these more susceptible hosts. On the typically more resistant Turkish and Nordmann firs,

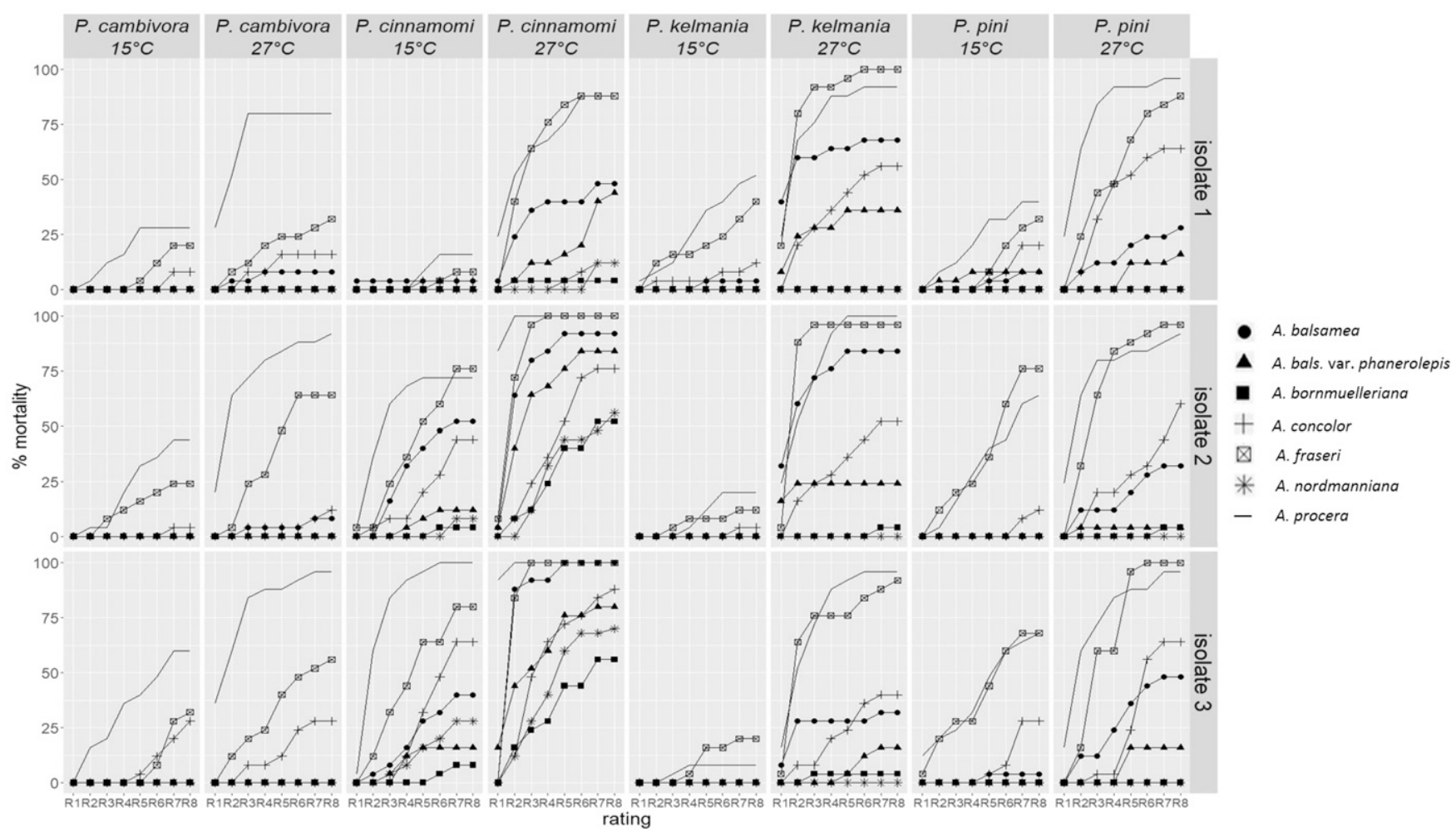

Fig. 3. Disease progress curves displaying mortality over 16 weeks for seven Abies species exposed to three isolates each of four Phytophthora species at two temperatures, 15 and $27^{\circ} \mathrm{C}$. The $\mathrm{x}$-axis indicates ratings (R1 to R8) made biweekly over the course of 16 weeks. Ratings were assessed by estimating the condition of the aboveground foliar parts of each plant on a 1 to 3 scale where 1 = alive, 2 = failing, and $3=$ dead. The number of dead trees (ratings of 3 ) were tallied and averaged across the five trees constituting an experimental unit, as well as across the five replicate blocks, to obtain a total percent mortality for each treatment at each rating date. 
root rot severity caused by $P$. kelmania, $P$. pini, and $P$. cambivora was rarely different from what was observed on control seedlings (Fig. 2). Phytophthora cambivora was arguably the least damaging Phytophthora, differing significantly from the other three treatments in nearly every fir species except for noble fir. Disease progress curves representing mortality over time illustrate the speed with which even more resistant Abies reached measurable levels of mortality with $P$. cinnamomi treatments and the relatively innocuous behavior of $P$. cambivora on most species aside from noble and Fraser firs (Fig. 3).

Observing differences in root rot severity and mortality based on isolate choice. Although not comparable statistically, visual

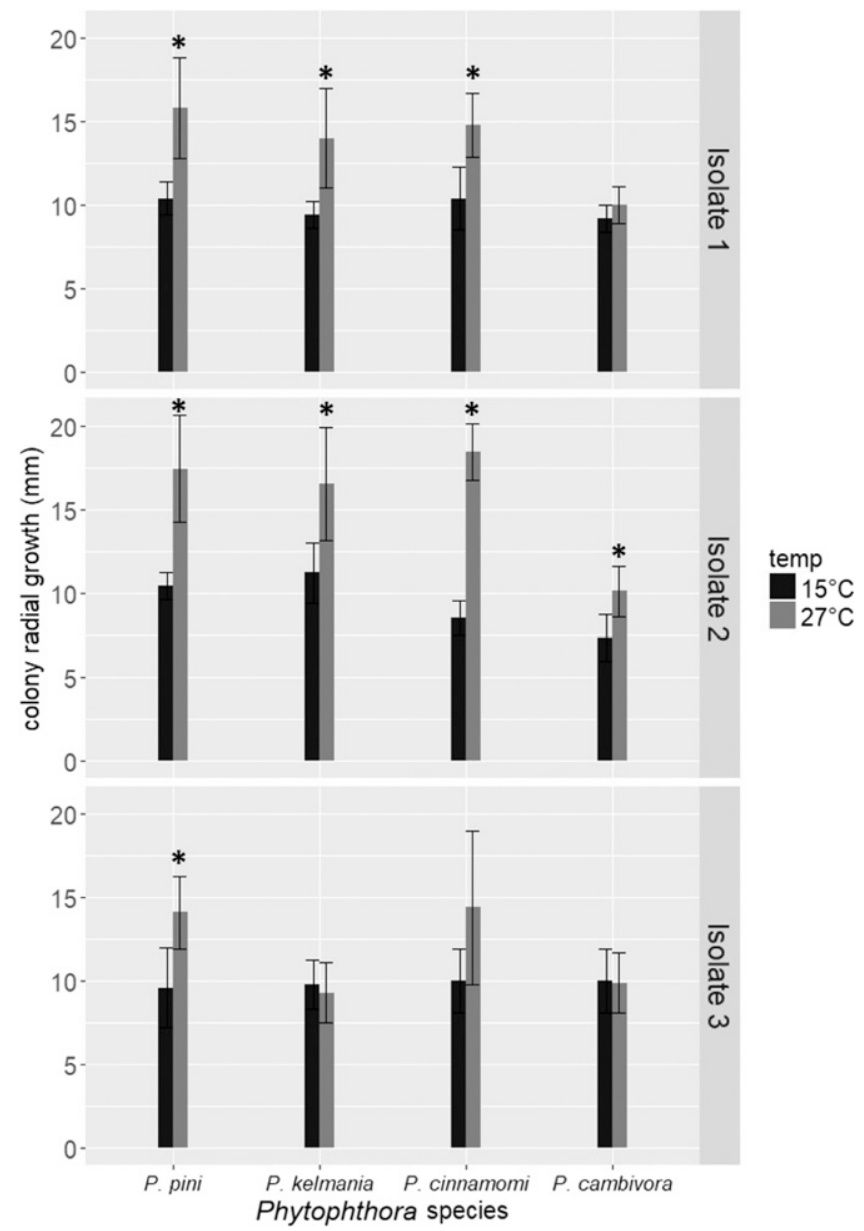

Fig. 4. In vitro radial growth (mm/day) of three isolates each of four species of Phytophthora at the two temperatures employed in the greenhouse study. Student's t-tests were used to assess differences in growth of each isolate for each Phytophthora species between the two temperatures. Statistically significant differences in growth between the two temperatures for a given Phytophthora isolate are indicated by stars above the bars. observation indicated that differences in root rot severity and mortality were minimal among distinct isolates of each Phytophthora species with the exception of $P$. cinnamomi. It was apparent that isolate 1 of this species caused less severe root damage and lower mortality rates than the other two isolates tested, particularly at cool temperatures and on more resistant hosts (Figs. 2 and 3).

Temperature effects on mortality, root rot, and pathogen vigor. Mortality was lower in the cooler greenhouse than under warmer ambient temperatures. Higher temperatures increased the speed and quantity of mortality of seedlings and increased the severity of root rot (Figs. 2 and 3). Replicated radial growth assays of all isolates of the Phytophthora species used in this experiment indicated that colony expansion on solid media tended to progress at a higher rate at 27 than $15^{\circ} \mathrm{C}$, although the differences were not statistically significant in some isolates (Fig. 4). Regression of radial growth rate against percent seedling mortality at 15 and $27^{\circ} \mathrm{C}$ indicated moderate positive correlations (average $R^{2}=0.45$ ) for balsam, white, Canaan, and Fraser firs. Radial growth rate was only weakly correlated with mortality in Nordmann, Turkish, and Noble firs (average $R^{2}=0.22$ ).

\section{Discussion}

Virulence test inoculations on noble fir seedling stems showed that distinct isolates of a given Phytophthora species varied little in their ability to cause lesions under the experimental conditions. The exception to this trend was observed in $P$. cinnamomi, for which isolate 05 produced statistically smaller lesions on noble fir stems (Fig. 1). This isolate was nevertheless included in the greenhouse rootinoculation experiments as $P$. cinnamomi isolate 1 to parallel studies performed by collaborating researchers that utilize this culture in $A$. fraseri inoculation studies in North Carolina. Although the design of the greenhouse root-inoculation study did not arrange for statistical comparison between isolates, it was apparent that $P$. cinnamomi isolate 1 also produced less severe root rot ratings, slightly larger biomass measurements, and noticeably slower disease progress on hosts in the greenhouse screening. Parallels between Phytophthora virulence on host stems and aggressiveness on roots have previously been established (Weiland et al. 2010), and observed variation among isolates of a given Phytophthora suggests that virulence testing as a means to characterize pathogen isolates prior to experiment initiation may be an important foundation for Phytophthora inoculation studies.

Inoculations performed at warmer temperatures resulted in overall greater mortality, higher percentages of rotted roots, and larger reductions in dry weight than identical treatments at cooler temperatures. Observations of more rapid radial growth of Phytophthora cultures on solid media at warmer temperatures implied that the pathogen may have an increased ability to colonize root tissues at higher temperatures. This idea was tested statistically by regressing radial growth rate against percent seedling mortality for each tree species. Moderately strong positive correlations supported this concept for balsam, white, Canaan, and Fraser firs; however, weak $R^{2}$ values for Nordmann, Turkish, and noble firs indicated that radial fungal growth rate was not likely as instrumental in causing mortality in

Table 4. Average percent mortality of seven Abies species after 16 weeks of exposure to three isolates each of four Phytophthora species at two temperatures. Percentages represent totals from all five blocks for each treatment. Analyses of variance were performed using the PROC MIXED procedure with post-hoc analysis using Tukey's honestly significant difference to determine mean separations between fir species. ${ }^{\mathrm{z}}$

\begin{tabular}{|c|c|c|c|c|c|c|c|c|c|c|c|c|c|c|c|c|c|c|c|c|c|c|c|c|}
\hline \multirow[b]{3}{*}{ Abies species } & \multicolumn{12}{|c|}{$15^{\circ} \mathrm{C}$ treatment } & \multicolumn{12}{|c|}{$27^{\circ} \mathrm{C}$ treatment } \\
\hline & \multicolumn{3}{|c|}{ P. cambivora } & \multicolumn{3}{|c|}{ P. cinnamomi } & \multicolumn{3}{|c|}{ P. kelmania } & \multicolumn{3}{|c|}{ P. pini } & \multicolumn{3}{|c|}{ P. cambivora } & \multicolumn{3}{|c|}{ P. cinnamomi } & \multicolumn{3}{|c|}{ P. kelmania } & \multicolumn{3}{|c|}{ P. pini } \\
\hline & 1 & 2 & 3 & 1 & 2 & 3 & 1 & 2 & 3 & 1 & 2 & 3 & 1 & 2 & 3 & 1 & 2 & 3 & 1 & 2 & 3 & 1 & 2 & 3 \\
\hline$\overline{\text { A. procera }}$ & $28 \mathrm{a}$ & $44 \mathrm{a}$ & $60 a$ & $16 \mathrm{a}$ & $72 \mathrm{ab}$ & $100 \mathrm{a}$ & $52 \mathrm{a}$ & $20 \mathrm{a}$ & $8 \mathrm{a}$ & $40 \mathrm{a}$ & $64 \mathrm{a}$ & $68 \mathrm{a}$ & $80 a$ & $92 \mathrm{a}$ & $96 \mathrm{a}$ & $88 \mathrm{a}$ & $100 \mathrm{a}$ & $100 \mathrm{a}$ & $92 \mathrm{a}$ & $100 \mathrm{a}$ & $96 \mathrm{a}$ & $96 \mathrm{a}$ & $92 \mathrm{a}$ & $\overline{96 \mathrm{a}}$ \\
\hline A. fraseri & $20 \mathrm{~b}$ & $24 \mathrm{a}$ & $32 \mathrm{~b}$ & $8 \mathrm{a}$ & $76 a$ & $80 \mathrm{~b}$ & $40 \mathrm{ab}$ & $12 \mathrm{a}$ & $20 \mathrm{a}$ & $32 \mathrm{ab}$ & $76 \mathrm{a}$ & $68 \mathrm{a}$ & $32 \mathrm{~b}$ & $64 \mathrm{~b}$ & $56 \mathrm{~b}$ & $88 \mathrm{a}$ & $100 \mathrm{a}$ & $100 \mathrm{a}$ & $100 \mathrm{a}$ & $96 \mathrm{a}$ & $92 \mathrm{a}$ & $88 \mathrm{ab}$ & $96 \mathrm{a}$ & $100 \mathrm{a}$ \\
\hline A. concolor & $8 \mathrm{~b}$ & $4 \mathrm{~b}$ & $28 \mathrm{~b}$ & $4 \mathrm{a}$ & $44 \mathrm{bcd}$ & $64 \mathrm{bc}$ & $12 \mathrm{ab}$ & $4 \mathrm{a}$ & $0 \mathrm{a}$ & $20 \mathrm{~b}$ & $12 \mathrm{~b}$ & $28 \mathrm{~b}$ & $16 \mathrm{bc}$ & $12 \mathrm{c}$ & $28 \mathrm{c}$ & $12 \mathrm{c}$ & $76 \mathrm{c}$ & $88 \mathrm{~b}$ & $56 \mathrm{~b}$ & $52 \mathrm{~b}$ & $40 \mathrm{~b}$ & $64 \mathrm{~b}$ & $60 \mathrm{~b}$ & $64 \mathrm{~b}$ \\
\hline A. balsamea & $0 \mathrm{~b}$ & $0 \mathrm{~b}$ & $0 \mathrm{~b}$ & $4 \mathrm{a}$ & $52 \mathrm{bc}$ & $40 \mathrm{~cd}$ & $4 \mathrm{~b}$ & $0 \mathrm{a}$ & $0 \mathrm{a}$ & $8 \mathrm{~b}$ & $0 \mathrm{~b}$ & $4 \mathrm{~b}$ & $8 \mathrm{bc}$ & $8 \mathrm{c}$ & $0 \mathrm{c}$ & $48 \mathrm{~b}$ & $92 \mathrm{ab}$ & $100 \mathrm{a}$ & $68 \mathrm{ab}$ & $84 \mathrm{a}$ & $32 \mathrm{~b}$ & $28 \mathrm{c}$ & $32 \mathrm{bc}$ & $48 \mathrm{~b}$ \\
\hline $\begin{array}{l}\text { A. balsamea var. } \\
\text { phanerolepis }\end{array}$ & $0 \mathrm{~b}$ & $0 \mathrm{~b}$ & $0 \mathrm{~b}$ & $0 \mathrm{a}$ & $12 \mathrm{~cd}$ & $16 \mathrm{~cd}$ & $0 \mathrm{~b}$ & $0 \mathrm{a}$ & $0 \mathrm{a}$ & $8 \mathrm{~b}$ & $0 \mathrm{~b}$ & $0 \mathrm{~b}$ & $0 \mathrm{c}$ & $0 \mathrm{c}$ & $0 \mathrm{c}$ & $44 \mathrm{bc}$ & $84 \mathrm{~b}$ & $80 \mathrm{bc}$ & $36 \mathrm{bc}$ & $24 \mathrm{bc}$ & $16 \mathrm{bc}$ & $16 \mathrm{c}$ & $4 \mathrm{c}$ & $16 \mathrm{c}$ \\
\hline A. nordmanniana & $0 \mathrm{~b}$ & $0 \mathrm{~b}$ & $0 \mathrm{~b}$ & $0 \mathrm{a}$ & $8 \mathrm{~d}$ & $28 \mathrm{~cd}$ & $0 \mathrm{~b}$ & $0 \mathrm{a}$ & $0 \mathrm{a}$ & $0 \mathrm{~b}$ & $0 \mathrm{~b}$ & $0 \mathrm{~b}$ & $0 \mathrm{c}$ & $0 \mathrm{c}$ & $0 \mathrm{c}$ & $12 \mathrm{c}$ & $56 \mathrm{c}$ & $70 \mathrm{bc}$ & $0 \mathrm{c}$ & $0 \mathrm{c}$ & $0 \mathrm{c}$ & $0 \mathrm{c}$ & $0 \mathrm{c}$ & $0 \mathrm{c}$ \\
\hline A. bornmuelleriana & $0 \mathrm{~b}$ & $0 \mathrm{~b}$ & $0 \mathrm{~b}$ & $0 \mathrm{a}$ & $4 \mathrm{~d}$ & $8 \mathrm{~d}$ & $0 \mathrm{~b}$ & $0 \mathrm{a}$ & $0 \mathrm{a}$ & $0 \mathrm{~b}$ & $0 \mathrm{~b}$ & $0 \mathrm{~b}$ & $0 \mathrm{c}$ & $0 \mathrm{c}$ & $0 \mathrm{c}$ & $4 \mathrm{c}$ & $52 \mathrm{c}$ & $56 \mathrm{c}$ & $0 \mathrm{c}$ & $4 \mathrm{c}$ & $4 \mathrm{c}$ & $0 \mathrm{c}$ & $4 \mathrm{c}$ & $0 \mathrm{c}$ \\
\hline
\end{tabular}

${ }^{\mathrm{z}}$ Letters next to measurements indicate significantly different mean mortality among the seven host species within each Phytophthora $\times$ isolate treatment. 
these species. Similarly, when evaluated on a by-host basis, multiple linear regression indicated that root dry weight was inadequate for forecasting AUDPC in Nordmann, Turkish, and noble firs (Table 3). Because these results were observed in two of the most disease-resistant species (Nordmann and Turkish firs) and the most susceptible species (noble fir), it is speculated that disease dynamics during host-Phytophthora interactions for species that fall on the extremes of the resistance spectrum could be directed more by root phenology or molecular interactions rather than pathogen vigor or maintenance of root mass. The actual mechanism of disease resistance or susceptibility to Phytophthora in Abies is as yet unknown, but microscopic evaluation of $P$. lateralis Tucker \& Milbrath infection of Port-Orford cedar (Chamaecyparis lawsoniana [A. Murray] Parl.) roots indicated that cortical cell invasion was retarded and vascular tissues were nonpenetrated in resistant roots, suggesting that resistance to PRR in conifers could be related to cellular interactions and root architecture (Oh and Hansen 2007). A concept that may explain the rendering of dry weight measurements inadequate for predicting host mortality includes that healthy roots may slowly regenerate over damaged roots, which would increase overall root biomass while still leaving the plant vulnerable to failure from disease. This occurrence has been observed in Douglas fir (Pseudotsuga menziesii [Mirb.] Franco) and Canaan fir (Frampton 1999; Hansen et al. 1980). Likewise, rapid mortality at warm temperatures could be owing to factors other than rapid fungal growth, such as increases in host transpiration rate owing to heat and a resulting deficit in moisture that is exacerbated by root deterioration.

Knowledge of how external factors affect symptom expression and potential resistance to PRR in the different species of Abies used as Christmas trees is critical to choosing the appropriate species to cultivate in high-incidence PRR sites. Findings from the greenhouse study indicate that Nordmann and Turkish firs are quite resistant to the four Phytophthora species tested but increase in sensitivity to $P$. cinnamomi as temperatures reach $27^{\circ} \mathrm{C}$ or greater. This trend implies that these species may do well in most parts of the country but are apt to fail in warm, moist areas where $P$. cinnamomi is pervasive such as the Piedmont region of North Carolina or irrigated Christmas tree fields in northeastern California. Canaan fir had root rot severity values statistically similar to resistant species but displayed greater disease progress than Nordmann or Turkish firs with $P$. cinnamomi, P. kelmania, and $P$. pini at $27^{\circ} \mathrm{C}$ (Figs. 2 and 3, Table 4). These results suggest that Canaan fir may be an appropriate species to cultivate in high-risk PRR sites in cooler areas such as the Pacific Northwest and Great Lakes states. Experimental values measured for balsam and white firs were intermediate between susceptible and resistant species, depending on the Phytophthora species and temperature. At high temperatures and with virulent Phytophthora species such as $P$. cinnamomi and $P$. kelmania, root rot severities for these Abies were high, whereas with $P$. pini and P. cambivora, particularly at lower temperatures, root rot severity corresponded more with resistant firs. Because $P$. cambivora and $P$. pini were the predominant Phytophthora species recovered from Christmas tree farms in the Pacific Northwest and New England, respectively (McKeever and Chastagner 2016), results from the greenhouse experiment suggest that cooler sites in these regions may be successful growing areas for these Abies species. Fraser and noble firs are recognized as the most PRR-susceptible species from the present study, suggesting that mortality may be expected with exposure to any of the Phytophthora species tested. However, if cultivation of these Abies hosts can be relegated to cooler sites, losses may be reduced to levels that may be acceptable in exchange for the high desirability of these species in the market.

The observed interactions among hosts, pathogen, and environment confirmed prior knowledge of the complexity of the PRR-Abies pathosystem and complemented previous research that indicates a lack of resistance in species such as Fraser and noble firs. Clarifications of how Phytophthora species and temperature affect host symptom expression may help to influence interpretation of ostensibly conflicting PRR research emerging from discrete geographic areas by acknowledging that the spectrum of resistances among species of Abies should be considered individually for each unique region. Implementation of a multifactorial approach illuminated the importance of Phytophthora isolate virulence and documented the contribution of ambient temperature to disease development. Knowledge of how temperature influences physiology and pathogen function may assist nursery managers and growers to manipulate environment as a means of disease avoidance, and delineation of the conditions under which more moderately resistant Abies species are apt to thrive may increase their utility as Christmas trees in lieu of highly susceptible firs.

\section{Acknowledgments}

The authors thank members of the Weyerhaeuser Corporation at the George R. Staebler Forest Resources Research Center in Centralia, WA, and the Rochester Seed Orchard in Rochester, WA, for the donation of the seedlings utilized in this research; Ken and JoAnn Scholz at the Snowshoe Evergreen Christmas Tree Farm and Nursery for their generous donations of seedling boxes and cold storage space for seedling vernalization; and the Washington State University Center for Interdisciplinary Statistical Education and Research for assistance with data analyses.

\section{Literature Cited}

Bhat, R. G., Colowit, P. M., Tai, T. H., Aradhya, M. K., and Browne, G. T. 2006 Genetic and pathogenic variation in Phytophthora cactorum affecting fruit and nut crops in California. Plant Dis. 90:161-169.

Campbell, C. L., and Neher, D. A. 1994. Estimating disease severity and incidence. Pages 117-147 in: Epidemiology and Management of Root Diseases. C. L. Campbell and D. M. Benson, eds. Springer, Berlin.

Campbell, S. J., and Hamm, P. B. 1989. Susceptibility of Pacific Northwest conifers to Phytophthora root rot. Ornamentals Northwest Arch. 13:5-8.

Chastagner, G. A., and Benson, D. M. 2000. The Christmas tree: Traditions, production, and diseases. Online. Plant Health Prog. 1.

Chastagner, G. A., Riley, K. L., and Hamm, P. B. 1990. Susceptibility of Abies spp. to seven Phytophthora spp. (Abstr.) Phytopathology 80:887.

Eggers, J. E., Balci, Y., and MacDonald, W. L. 2012. Variation among Phytophthora cinnamomi isolates from oak forest soils in the eastern United States. Plant Dis. 96:1608-1614.

Frampton, J. 1999. Evaluating alternative fir species for Phytophthora root rot resistance. Limbs Needles 26:7, 10.

Frampton, J., and Benson, D. M. 2004. Phytophthora root rot mortality in Fraser fir seedlings. HortScience 39:1025-1026.

Frampton, J., and Benson, D. M. 2012. Seedling resistance to Phytophthora cinnamomi in the genus Abies. Ann. For. Sci. 69:805-812.

Granke, L. L., Quesada-Ocampo, L. M., and Hausbeck, M. K. 2011. Variation in phenotypic characteristics of Phytophthora capsici isolates from a worldwide collection. Plant Dis. 95:1080-1088.

Hamm, P. B., and Hansen, E. M. 1982. Pathogenicity of Phytophthora species to Pacific Northwest conifers. Eur. J. Forest Pathol. 12:167-174.

Hansen, E. M., Roth, L. F., Hamm, P. B., and Julis, A. J. 1980. Survival, spread, and pathogenicity of Phytophthora spp. on Douglas-fir seedlings planted on forest sites. Phytopathology 70:422-425.

Hinesley, L. E., Parker, K. C., and Benson, D. M. 2000. Evaluation of seedlings of Fraser, Momi, and Siberian fir for resistance to Phytophthora cinnamomi. HortScience 35:87-88.

Hodgson, W. A., and Sharma, K. P. 1967. Restoration of virulence of stored cultures of Phytophthora infestans. Can. J. Plant Sci. 47:447-449.

Holmes, K. A., and Benson, D. M. 1994. Evaluation of Phytophthora parasitica var. nicotianae for biocontrol of Phytophthora parasitica on Catharanthus roseus. Plant Dis. 78:193-199.

Horsfall, J. G., and Barratt, R. W. 1945. An improved grading system for measuring plant disease. (Abstr.) Phytopathology 35:655.

Kuan, T. L., and Erwin, D. C. 1980. Predisposition effect of water saturation of soil on Phytophthora root rot of alfalfa. Phytopathology 70:981-986.

Madden, L. V., Hughes, G., and van den Bosch, F. 2007. The Study of Plant Disease Epidemics. APS Press, St. Paul, MN.

McKeever, K. M., and Chastagner, G. A. 2016. A survey of Phytophthora species associated with Abies in U.S. Christmas tree farms. Plant Dis. 100: 1161-1169.

Oh, E., and Hansen, E. M. 2007. Histopathology of infection and colonization of susceptible and resistant Port-Orford-cedar by Phytophthora lateralis. Phytopathology 97:684-693.

Rhoades, C. C., Brosi, S. L., Dattilo, A. J., and Vincelli, P. 2003. Effect of soil compaction and moisture on incidence of Phytophthora root rot on American chestnut (Castanea dentata) seedlings. For. Ecol. Manage. 184 47-54.

Shew, H. D., and Benson, D. M. 1981. Fraser fir root rot induced by Phytophthora citricola. Plant Dis. 65:688-689.

Weiland, J. E., Nelson, A. H., and Hudler, G. W. 2010. Aggressiveness of Phytophthora cactorum, P. citricola I, and $P$. plurivora from European beech. Plant Dis. 94:1009-1014. 